\title{
Application of instrumental methods for quality control of lactoferrin and raw materials for its production
}

\author{
Elena Zhilyakova ${ }^{1}$, Maria Chernyshova ${ }^{2}$, Irina Spichak $^{1}$, Dariya Fadeeva $^{1^{*}}$, Vladimir \\ Sherstyukov $^{3}$, Valentina Kazakova ${ }^{1}$, Alexey $\mathrm{Khmyrov}^{1}$, and Veronica Ivanova ${ }^{1}$ \\ ${ }^{1}$ Belgorod State National Research University, 308015, Belgorod, Russia \\ ${ }^{2}$ VIC Animal Health LLC, 308519, Belgorod, Russia \\ ${ }^{3}$ Branch of SC "VEROPHARM", 308013, Belgorod, Russia
}

\begin{abstract}
Bovine cattle milk lactoferrin is industrially produced from cow's milk and used in a variety of functional products, including baby food, nutritional supplements, dairy products, and veterinary drugs. The possibility of obtaining lactoferrin from lactic acid milk wheyrises a particular interest. The purpose of this study is to assess the possibility of using and adapting existing spectrophotometric methods for determining the concentration of total protein and an electrophoretic method for analyzing the protein composition of whey fractions and lactoferrin substances. A comparative study of two methods for determining the total protein in whey fractions and lactoferrin preparations - biuret and Bradford method was carried out. The validation parameters of both methods were defined. An analytical range from $30 \mu \mathrm{g} / \mathrm{ml}$ to $1000 \mu \mathrm{g} / \mathrm{ml}$ characterizes the linearity of the Bradford method. The electrophoretic profile of milk, milk whey, whey fractions and substances of lactoferrinwere analyzed. The results obtained indicate a high information content of the electrophoretic method for characterizing the purification efficiency of whey fractions. Keywords: lactoferrin, spectrophotometric methods, functional products
\end{abstract}

\section{Introduction}

Lactoferrin is a multifunctional iron-binding protein of the transferrin family [1]. In the organism of mammals, it is part of various secretory fluids and has a wide range of biological activities [2]. Lactoferrin accumulates in neutrophils, and its increased concentration is found in inflammation sites. The biological activity of lactoferrinis established by the ability to bind iron ions and the presence of hydrophobic and charged areas on the protein surface. In addition, specific receptors for this protein have been found on the cell surface. The high binding constant of iron is due to the presence of an alphahelix in the bridge that binds two domains of this protein [3].

*Corresponding author:fadeeva@bsu.edu.ru 
Bovine cattle milk lactoferrinis industrially produced from cow's milk and used in a variety of functional products, including baby food, nutritional supplements, dairy products, veterinary drugs. The cost of bovine cattle milk lactoferrin used in the food industry and pharmaceuticals is quite high. Currently, the world has adopted two quality standards for commercial bovine lactoferrin - Novel Food ("new food products") and GRAS ("generally recognized as safe") in the EU and the US, respectively. These standards regulate the high purity of lactoferrin (over 95\%) in the manufactured product. [4].

The possibility of obtaining lactoferrin from lactic acid milk whey, which is currently a waste in the production of dairy products and for the most part is not recycled, rises a particular interest.

One of the first stages of research on the development of an industrial technology for producing lactoferrin of proper quality from milk and milk whey is the selection, adaptation and validation of lactoferrin test methods. One of the main methods for assessing the quality of raw materials for the production of lactoferrin is the method for determining the total protein, as well as assessing the content of protein components by electrophoresis [6].

The purpose of this study is to assess the possibility of using and adapting existing spectrophotometric methods for determining the concentration of total protein and an electrophoretic method for analyzing the protein composition of whey fractions and lactoferrin substances.

\section{Material and methods}

Study objects: standard sample of cow's milk lactoferrin (90\% purity), Sigma (L9507), commercial lactoferrin preparations (the Netherlands, China, Russia), protein molecular weight markers, pre-stained with 10-245 kDa, Prism Ultra, (Roth, Germany).

Following equipment was used in the research:

1)Vertical Electrophoresis System VE-20 («Helicon», Russia);

2)SpectrophotometerUV - 2600 («Shimadzu», Japan);

3)Protein determination kit by biuret method Roti-Quant Universal («Roth», Germany);

4)Protein determination kit by Bradford method Roti-Quant («Roth», Germany).

Preparation of solutions for electrophoresis in polyacrylamide gel:

- electrode buffer solution (25 mMtris-glycine buffer, $\mathrm{pH} \mathrm{8.3):} 4.54 \mathrm{~g}$ of tris was dissolved in $1 \mathrm{~L}$ of milliQ water and titrated with glycine $(28.15 \mathrm{~g})$ until $\mathrm{pH} 8.3$. Then $1.5 \mathrm{~g}$ of sodium dodecyl sulphatewas added, stirred until complete dissolution, avoiding foaming of the solution. The volume was brought up to 1.51 with milliQ water.

- $10 \%$ sodium dodecyl sulphate solution: $1 \mathrm{~g}$ of sodium dodecyl sulfate was dissolved with stirring in $100 \mathrm{ml}$ of milliQ water.

- $10 \%$ solution of bromophenol blue: $50 \mathrm{mg}$ of bromophenol blue was dissolved in $5 \mathrm{ml}$ of milliQ water.

- $10 \%$ sodium persulphate solution: $1 \mathrm{~g}$ of sodium persulphate was dissolved in $5 \mathrm{ml}$ of milliQ water, mixed, the volume was brought up to $10 \mathrm{ml}$. The solution was divided into 1 $\mathrm{ml}$ aliquots.

- buffer for separating gel (1 M tris-HCl buffer, $\mathrm{pH} 8.8)$ : $12.114 \mathrm{~g}$ of tris was dissolved in milliQ water, titrated with $6 \mathrm{M}$ hydrochloric acid solution to $\mathrm{pH} 8.8$. The final volume of the solution was brought up to $100 \mathrm{ml}$ with milliQ water.

- buffer for stacking gel (1 M tris-HCl buffer, $\mathrm{pH} 6.8)$ : $12.114 \mathrm{~g}$ of tris was dissolved in milliQ water, titrated with $6 \mathrm{M}$ hydrochloric acid solution to $\mathrm{pH} 6.8$. The final volume of the solution was brought up to $100 \mathrm{ml}$ with milliQ water.

- sample buffer $(10 \mathrm{ml}): 0.5 \mathrm{ml}$ concentrating gel buffer, $2.0 \mathrm{ml} 10 \%$ sodium dodecyl sulphate solution, $0.1 \mathrm{ml} 10 \%$ bromophenol blue solution, $0.154 \mathrm{~g}$ dithiothreitol, $1.25 \mathrm{~g}$ glycerin were mixed and $6.4 \mathrm{ml}$ milliQ water was added. 
- stock monomer solution for polyacrylamide gel $(100 \mathrm{ml}): 1 \mathrm{~g}$ of methylenebisacrylamide was dissolved on a stirrer at room temperature in 1-20 ml of milliQ water. After complete dissolution, $29 \mathrm{~g}$ of acrylamide was added. After complete dissolution, the volume of the solution was brought up to $100 \mathrm{ml}$ with milliQ water.

- agarose solution for glass sealing: $1 \mathrm{~g}$ of agarose was dissolved with heating in $100 \mathrm{ml}$ of electrode buffer.

Preparation of lactoferrin standard sample stock solution (biuret method).

Lactoferrin standard sample (accurately weighed) was added in a volumetric flask with a capacity of $25 \mathrm{ml} 50.0 \mathrm{mg}$ of the volume was brought to the mark with water (MilliQ) and thoroughly mixed, avoiding strong foaming. The concentration of lactoferrin in the stock solution of the standard sample should be $2.0 \pm 0.2 \mathrm{mg} / \mathrm{ml}$.

Preparation of lactoferrin standard sample work solutions (biuret method):

The preparation of lactoferrin standard sample work solutions was carried out in accordance with Table 1.

Table 1. Preparation of lactoferrin standard sample work solutions (determination of total protein by biuret method)

\begin{tabular}{|c|c|c|c|c|}
\hline \multirow{2}{*}{$\begin{array}{c}\text { Work } \\
\text { solution }\end{array}$} & \multicolumn{2}{|c|}{ Stock solution volume } & V of MilliQ water, ml & S LF, mg/ml \\
\cline { 2 - 5 } & Solution & V, ml & & \\
\hline A & stock & 0,4 & 0 & \\
\hline B & stock & 0,375 & 0,125 & 2,003 \\
\hline C & stock & 0,325 & 0,325 & 1,502 \\
\hline D & B & 0,325 & 0,325 & 1,001 \\
\hline E & C & 0,325 & 0,325 & 0,751 \\
\hline F & E & 0,325 & 0,325 & 0,501 \\
\hline G & F & 0,325 & 0,325 & 0,250 \\
\hline H & G & 0,3 & 0,45 & 0,050 \\
\hline I & G & 0,1 & 0,4 & 0,025 \\
\hline K & I & 0,1 & 0,4 & 0,005 \\
\hline BLANK & 0 & 0 & 0,4 & 0,000 \\
\hline
\end{tabular}

Preparation of lactoferrin standard sample stock solution (Bradford method)

Lactoferrin standard sample (accurately weighed) was added in a volumetric flask with a capacity of $25 \mathrm{ml} 25.0 \mathrm{mg}$ of, the volume was brought to the mark with water (MilliQ) and thoroughly mixed, avoiding strong foaming. The concentration of lactoferrin in the stock solution of the standard sample should be $1.0 \pm 0.1 \mathrm{mg} / \mathrm{ml}$.

Preparation of lactoferrin standard sample work solutions (Bradford method).

The preparation of lactoferrin standard sample work solutions was carried out in accordance with Table 2 .

Table 2. Preparation of lactoferrin standard sample work solutions (determination of total protein by Bradford method)

\begin{tabular}{|c|c|c|c|c|}
\hline \multirow{2}{*}{$\begin{array}{c}\text { Work } \\
\text { solution }\end{array}$} & \multicolumn{2}{|c|}{ Stock solution volume } & V of MilliQ & S, $\mathbf{m g} / \mathbf{m l}$ \\
\cline { 2 - 3 } water, $\mathbf{~ m l}$ & Solution & V, ml & 0 & 1,000 \\
\hline A & stock & 0,5 & 0,5 & 0,500 \\
\hline B & stock & 0,5 & 0,5 & 0,250 \\
\hline C & B & 0,5 & 0,5 & 0,125 \\
\hline D & C & 0,5 & 0,5 & 0,063 \\
\hline E & D & 0,5 & 0,5 & 0,000 \\
\hline BLANK & & 0 & & \\
\hline
\end{tabular}


To assess the applicability of spectrophotometric methods for determining the concentration of total protein in whey fractions and lactoferrin preparations, the following validation characteristics were used: analytical range, linearity, accuracy, precision, repeatability [5].

The study of linearity, accuracy, repeatability and intermediate precision was carried out using lactoferrin standard sample solutions, prepared in duplicate, on two independent days. The studies were carried out at 5-10 concentration levels of lactoferrin standard sample.

Protein electrophoresis in polyacrylamide gel was carried out in accordance with the instruction [6], with modifications. Polyacrylamide gel was prepared immediately prior the experiment. Ammonium persulfate was used as a polymerization initiator, and tetramethylethylenediamine was used as a catalyst. The mixture to form a gel (consisting of acrylamide solution, bisacrylamide, buffer, sodium dodecyl sulfate, initiator and catalyst) was poured between the glasses using a priming chamber. After the gel block has polymerized, it can be used for separation in the electrophoresis chamber.

\section{Results and discussion}

The applicability of two methods of spectrophotometric determination of the total protein concentration for the analysis of milk and whey fractions and determination of the purity of lactoferrin substances was analyzed in this work. Applicability was assessed based on the validation characteristics of methods such as linearity, accuracy, precision, repeatability and analytical range.

Figure 1 shows the data of the dependence of absorbance on the concentration of lactoferrin in the samples. It was found that the linearity of the dependence of the solution absorbance on the concentration of lactoferrin when using the biuret method is characterized by a rather narrow analytical range - from $5 \mu \mathrm{g} / \mathrm{ml}$ to $400 \mu \mathrm{g} / \mathrm{ml}$.

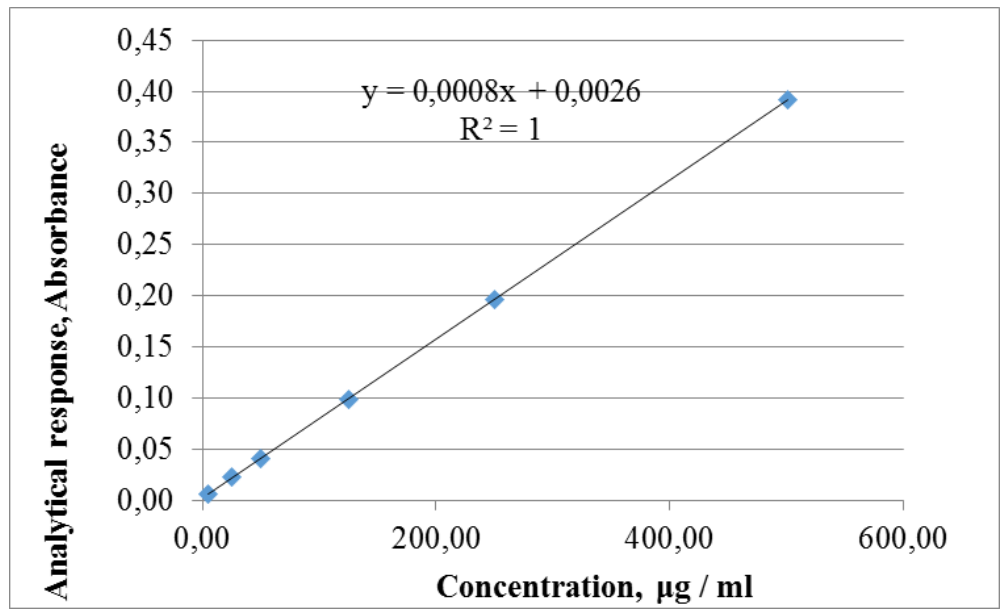

Fig. 1. Dependence of absorbance on the concentration of lactoferrin in samples when determining the protein concentration by the biuret method

The results of studying the linearity and the degree of obtained data variability when analyzing lactoferrin standard sample solutions by the biuret method in the range from $5 \mu \mathrm{g} / \mathrm{ml}$ to $500 \mu \mathrm{g} / \mathrm{ml}$ are presented in Tables 3 and 4 .

The presented data indicate the significance of the regression. The correlation index $r$ was 0.9999 , which meets the necessary criteria $(r \geq 0.99236)$. Coefficient "a" is statistically indistinguishable from zero. The $\mathrm{s} 0 / \mathrm{b}$ parameter is less than the $\Delta \mathrm{As} / \mathrm{t}$ parameter $(95 \%$, 
n-2), which includes the maximum permissible analytical uncertainty. The one-sided confidence interval $(\Delta \mathrm{a})$ of the scatter points around a straight line does not exceed the maximum permissible analytical uncertainty $(\Delta \mathrm{As})$.

Table 3. Results of evaluating the linearity of lactoferrin concentration determination by the biuret method in the range from $5 \mu \mathrm{g} / \mathrm{ml}$ to $500 \mu \mathrm{g} / \mathrm{ml}$

\begin{tabular}{|c|c|}
\hline Parameter & Value \\
\hline Coefficient a & 0,0012 \\
\hline Standard deviation for the y-axis intercept $(\mathrm{sa})$ & 0,0004 \\
\hline t-criteria $(95 \%, \mathrm{n}-2), \mathrm{n}=9$ & 2,7800 \\
\hline Confidential interval $\Delta \mathrm{a}$ & 0,0026 \\
\hline Coefficient b & 0,0008 \\
\hline Residual standard deviation $(\mathrm{s} 0)$ & 0,0008 \\
\hline Parameter $(\mathrm{s} 0 / \mathrm{b})$ & 1,0271 \\
\hline Parameter $(\Delta$ As/ $(\mathrm{t}(95 \%, \mathrm{n}-2))$ & 1,1511 \\
\hline Correlation index r & 3,2000 \\
\hline Maximum permissible analytical uncertainty $(\Delta \mathrm{As})$ & 0,99999 \\
\hline
\end{tabular}

Table 4. Mean value and relative standard deviation (RSD) of the obtained values of sample absorbance

\begin{tabular}{|c|c|c|c|c|c|c|}
\hline \multirow{2}{*}{$\begin{array}{c}\text { Sample } \\
\text { No. }\end{array}$} & \multirow{2}{*}{$\mathbf{S}, \boldsymbol{\mu g} / \mathbf{m l} \mathbf{l}$} & \multicolumn{3}{|c|}{ Absorbance } & \multirow{2}{*}{ Mean } & \multirow{2}{*}{ RSD, $\%$} \\
\hline & & 1 & 2 & 3 & & \\
\hline 1 & 500,70 & 0,392 & 0,392 & 0,391 & 0,392 & 0,147 \\
\hline 2 & 250,35 & 0,197 & 0,197 & 0,195 & 0,196 & 0,588 \\
\hline 3 & 125,18 & 0,099 & 0,099 & 0,100 & 0,099 & 0,581 \\
\hline 4 & 50,07 & 0,041 & 0,040 & 0,041 & 0,041 & 1,420 \\
\hline 5 & 25,04 & 0,023 & 0,023 & 0,023 & 0,023 & 0,000 \\
\hline 6 & 5,01 & 0,007 & 0,007 & 0,007 & 0,007 & 0,000 \\
\hline
\end{tabular}

Based on the absorbance data obtained as a result of three-fold analysis of lactoferrin samples containing the analyte in a known concentration, the method accuracy was determined (table 5).

Table 5. Protein concentration test accuracy, using biuret method

\begin{tabular}{|c|c|c|c|c|}
\hline $\begin{array}{c}\text { Sample } \\
\text { No. }\end{array}$ & $\begin{array}{c}\text { S lactoferrin, } \boldsymbol{\mu g} / \mathbf{m l} \\
\text { (spiked) }\end{array}$ & $\begin{array}{c}\mathbf{A} \mathbf{5 0 3} \mathbf{~ n m} \\
\mathbf{( n = 3 )}\end{array}$ & $\begin{array}{c}\text { S lactoferrin, } \\
\mathbf{m g} / \mathbf{m l} \text { (recovered) }\end{array}$ & Accuracy, \% \\
\hline 1 & 500,70 & 0,391667 & 501,28 & 100,12 \\
\hline 2 & 250,35 & 0,196333 & 249,59 & 99,70 \\
\hline 3 & 125,18 & 0,099333 & 124,61 & 99,55 \\
\hline 4 & 50,07 & 0,040667 & 49,01 & 97,89 \\
\hline 5 & 25,04 & 0,023 & 25,44 & 101,62 \\
\hline 6 & 5,01 & 0,007 & 5,11 & 102,06 \\
\hline
\end{tabular}

It was found that the deviation of the calculated amount of lactoferrin in the standardized test solutions relative to the reference solution does not exceed $2 \%$ of the applied amount, which meets the necessary criteria. Thus, the criterion of practical insignificance is fulfilled.

The one-sided confidence interval $(\Delta \mathrm{Z})$ (spiked / detected, Z, \%) was 2.04, which does not exceed the maximum permissible analytical uncertainty $(\Delta \mathrm{As}) 3.2$, which, in turn, indicates the required method precision. 
The relative standard deviation (RSD) of accuracy indicators was $1.514 \%$ (Table 6.3), which does not exceed the acceptance criterion when calculating the repeatability (RSD $\leq$ 2\%).

Based on the accuracy data obtained by two operators on different days, the RSD of the lactoferrin recovery was $1.514 \%$ for one operator and $1.437 \%$ for the second. The obtained values do not exceed the acceptance criterion ( $\mathrm{RSD} \leq 2.0 \%$ ).

Thus, the data obtained indicate the possibility of using the biuret method as a control method for determining the concentration of total protein in the development of laboratory, pilot and industrial technology for the production of lactoferrin from whey, and proper quality control of the final product. However, the use of this method is limited by a rather narrow analytical range: from 0.005 to $0.5 \mathrm{mg} / \mathrm{ml}$.

The next stage of research was the approbation of the Bradford method for determining the total protein. Figure 2 shows the data of the dependence of absorbance on the concentration of lactoferrin in the samples. The linearity of the absorbance solution dependence on the concentration of lactoferrin when using the Bradford method is characterized by an analytical range from $30 \mu \mathrm{g} / \mathrm{ml}$ to $1000 \mu \mathrm{g} / \mathrm{ml}$.

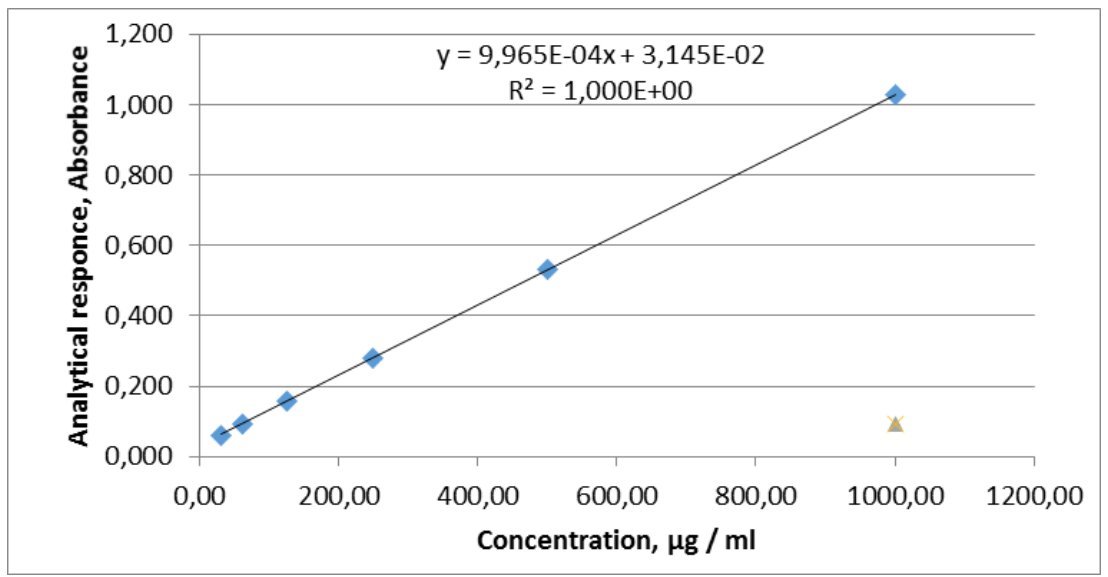

Fig. 2. Dependence of absorbance on the concentration of lactoferrin in samples when determining the protein concentration by the Bradford method

The results of studying the linearity and the obtained data variability when analyzing lactoferrin standard samples solutions by the Bradford method in the range from $30 \mu \mathrm{g} / \mathrm{ml}$ to $1000 \mu \mathrm{g} / \mathrm{ml}$ are presented in tables 6 and 7 .

The presented data indicate the significance of the regression. The correlation index $r$ is 1.0 , which meets the necessary criteria $(\mathrm{r} \geq 0.99236)$. Coefficient "a" is statistically indistinguishable from zero. The $\mathrm{s}_{0} / \mathrm{b}$ parameter is less than the $\Delta_{\mathrm{As}} / \mathrm{t}$ parameter $(95 \%, \mathrm{n}$ 2 ), which includes the maximum permissible analytical uncertainty.

Thus, the one-sided confidence interval $\left(\Delta_{\mathrm{A}}\right)$ of the scatter points around a straight line does not exceed the maximum permissible analytical uncertainty $\left(\Delta_{\mathrm{As}}=3.2\right)$.

Based on the absorbance data obtained as a result of three-fold analysis of lactoferrin samples containing the analyte in a known concentration, the method accuracy was determined (Table 8). 
Table 6. Results of evaluating the linearity of lactoferrin concentration determination bythe Bradford method

\begin{tabular}{|c|c|}
\hline Parameter & Value \\
\hline Coefficient a & 0,0314 \\
\hline Standard deviation for the y-axis intercept $\left(\mathrm{s}_{\mathrm{a}}\right)$ & 0,0005 \\
\hline $\mathrm{t}$-criteria $(95 \%, \mathrm{n}-2), \mathrm{n}=9$ & 2,7800 \\
\hline Confidential interval $\Delta_{\mathrm{a}}$ & 0,0014 \\
\hline Coefficient $\mathrm{b}$ & 0,0010 \\
\hline Residual standard deviation $\left(\mathrm{s}_{0}\right)$ & 0,0009 \\
\hline Parameter $(\mathrm{s} 0 / \mathrm{b})$ & 0,9172 \\
\hline Parameter $\left(\Delta_{\mathrm{As}} / \mathrm{t}_{(95 \%, \mathrm{n}-2)}\right)$ & 1,1511 \\
\hline Correlation index r & 3,2000 \\
\hline
\end{tabular}

Table 7. Mean value and relative standard deviation (RSD) of the obtained values of sample absorbance

\begin{tabular}{|c|c|c|c|c|c|c|}
\hline $\begin{array}{c}\text { Sample } \\
\text { No. }\end{array}$ & \multirow{2}{*}{$\mathrm{S}, \mu \mathrm{g} / \mathrm{ml}$} & \multicolumn{3}{|c|}{ Absorbance } & \multirow{2}{*}{ Mean } & \multirow{2}{*}{ RSD, $\%$} \\
\cline { 3 - 5 } & 1 & 2 & 3 & & \\
\hline 1 & 1001,400 & 1,029 & 1,029 & 1,030 & 1,029 & 0,056 \\
\hline 2 & 500,700 & 0,530 & 0,531 & 0,530 & 0,530 & 0,109 \\
\hline 3 & 250,350 & 0,281 & 0,280 & 0,281 & 0,281 & 0,206 \\
\hline 4 & 125,175 & 0,158 & 0,157 & 0,157 & 0,157 & 0,367 \\
\hline 5 & 62,588 & 0,095 & 0,094 & 0,094 & 0,094 & 0,612 \\
\hline 6 & 31,294 & 0,062 & 0,061 & 0,061 & 0,061 & 0,000 \\
\hline
\end{tabular}

Table 8. Protein concentration test accuracy, using Bradford method

\begin{tabular}{|c|c|c|c|c|}
\hline $\begin{array}{c}\text { Sample } \\
\text { No. }\end{array}$ & $\begin{array}{c}\text { S lactoferrin, } \mu \mathrm{g} / \mathrm{ml} \\
\text { (spiked) }\end{array}$ & $\begin{array}{c}\text { A 595 } \mathrm{nm} \\
(\mathrm{n}=3)\end{array}$ & $\begin{array}{c}\text { S lactoferrin, } \\
\mathrm{mg} / \mathrm{ml} \\
\text { (recovered) }\end{array}$ & Accuracy, \% \\
\hline 1 & 1001,40 & 1,029 & 1000,87 & 99,95 \\
\hline 2 & 500,70 & 0,530 & 500,37 & 99,93 \\
\hline 3 & 250,35 & 0,281 & 249,96 & 99,84 \\
\hline 4 & 125,18 & 0,157 & 126,26 & 100,86 \\
\hline 5 & 62,59 & 0,094 & 63,07 & 100,77 \\
\hline 6 & 31,29 & 0,061 & 31,22 & 99,76 \\
\hline
\end{tabular}

It was found that the deviation of the calculated amount of lactoferrin in the standardized test solutions relative to the reference solution does not exceed $2 \%$ of the applied amount, which meets the necessary criteria. Thus, the criterion of practical insignificance is fulfilled.

The one-sided confidence interval $(\Delta \mathrm{Z})$ (spiked / detected, Z, \%) was 0.393 , which does not exceed the maximum permissible analytical uncertainty $\left(\Delta_{\mathrm{As}}\right) 3.2$, which, in turn, indicates the required method precision.

The relative standard deviation (RSD) of accuracy indicators was 0,491\% (Table 6.6), which does not exceed the acceptance criterion when calculating the repeatability (RSD $\leq$ $2 \%$ ).

Based on the accuracy data obtained by two operators on different days, the RSD of the lactoferrin recovery was $0,491 \%$ for one operator and $0,546 \%$ for the second. The obtained values do not exceed the acceptance criterion $(\mathrm{RSD} \leq 2.0 \%)$. 
Thus, the data obtained indicate the possibility of using Bradford method as a control method for determining the concentration of total protein in the development of laboratory, pilot and industrial technology for the production of lactoferrin from whey, and proper quality control of the final product. The use of the Bradford method is preferable in comparison with the biuret method, since the Bradford method has a wider analytical range, is easy to apply and less time consuming.

Based on the above data, Bradford method was chosen as the preferred method for determining the concentration of total protein in lactoferrin substances. Using this method, the protein content was determined in commercial preparations of lactoferrin produced in China (sample No. 1) - 98.2\%, the Netherlands (sample No. 2) - 97.9\% and Russia (sample No. 3) $-42.23 \%$.

Table 9 shows the data of protein content analysis in defatted milk, milk whey and whey fractions obtained in the process of ultrafiltration using filters with different pore diameters.

Table 9. Protein content in defattedmilk, milkwhey and whey fractions (determined by Bradford method)

\begin{tabular}{|c|c|}
\hline Sample & Protein content, $\%$ \\
\hline Defatted milk & 3,64 \\
\hline Milk whey & 0,844 \\
\hline Whey fraction $(\geq 100 \mathrm{kDa}$ ) & 0,741 \\
\hline Whey fraction (from 10 to $100 \mathrm{kDa}$ ) & 0,572 \\
\hline
\end{tabular}

Also, within the framework of the study, an analysis of the protein composition of whey fractions and lactoferrin substances was carried out. Figure 3 shows the electrophoretic profile of cheese whey fractions and lactoferrin substances. It was found that when using a $12.5 \%$ polyacrylamide gel, an optimal distribution of protein fractions is achieved, which makes it possible to characterize the protein composition of the sample and, accordingly, its purity. As can be seen from the data presented, sample No. 1 (China) is characterized by the highest purity. Sample No. 2 of lactoferrin (the Netherlands) is characterized by the presence of two additional minor protein bands, differing in molecular weight from lactoferrin. The least pure is sample No. 3 (Russia).

Figure 4 shows the protein profile of milk, milk whey and whey fractions obtained during ultrafiltration using filters with different pore diameters. The presented data testify to the high information content of the electrophoretic method for characterizing the degree of whey fractions purification. Thus, electrophoresis in $12.5 \%$ polyacrylamide gel is fully applicable as a method for controlling the technological process of isolation and purification of lactoferrin from whey.

\section{Conclusion}

A study of the applicability of two spectrophotometric analytic methods to determine the concentration of total protein in milk, whey, whey fractions and lactoferrin substances wascarried out. The validation parameters were defined for biuret and Bradford methods. It was determined that both methods are applicable for use as a control method suitable both for use in the development of laboratory, pilot and industrial technology for the production of lactoferrin from whey, and for the properquality control of the final product. However, the use of the Bradford methodis more preferable in comparison with the biuret method, since the Bradford method has a wider analytical range, is easy to apply and less time consuming. 
Approved methods were used to study the content of total protein in three commercial preparations of lactoferrin, as well as in raw materials and semi-finished products of milk and whey.

The approbation and optimization of the method of denaturing electrophoresis in polyacrylamide gel was carried out for its use as a method for controlling the intermediate stages of lactoferrin production from whey, as well as a method for controlling the purity of the final product. The full applicability and high information content of the electrophoretic method for characterizing the degree of purification of whey fractions and the purity of the final product has been demonstrated.

The protein profile of three commercial preparations of lactoferrin, as well as rawmaterials and intermediates of milk and whey, has been characterized.

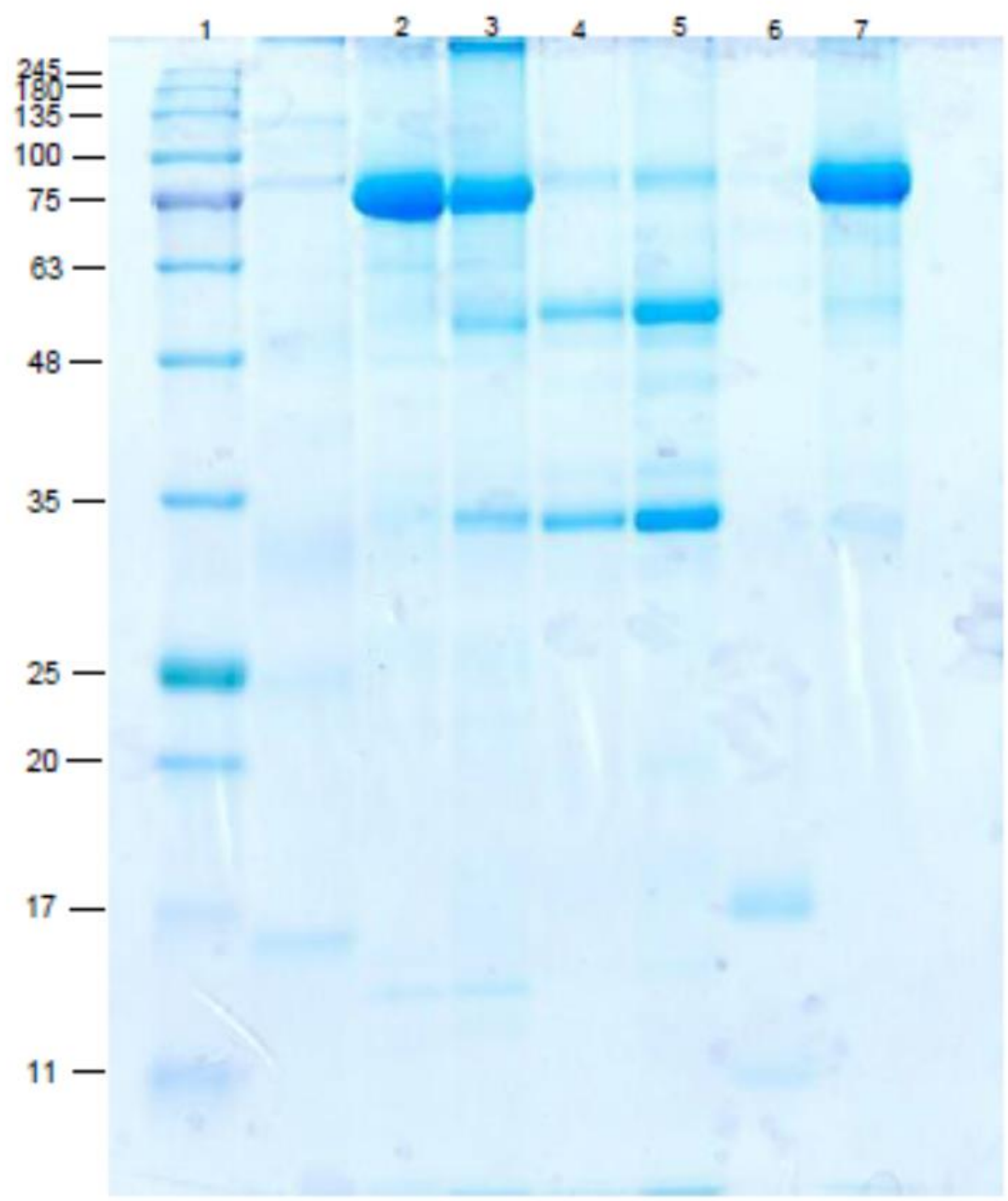

Fig.3. Electropherogram of whey and lactoferrin substances: (1) molecular weight markers, (2) lactoferrin sample No. 1, (3) lactoferrin sample No. 2, (4) lactoferrin sample No. 3 (powder), (5) lactoferrin sample No. 1 (liquid), (6) whey, (7) lactoferrin standard sample 


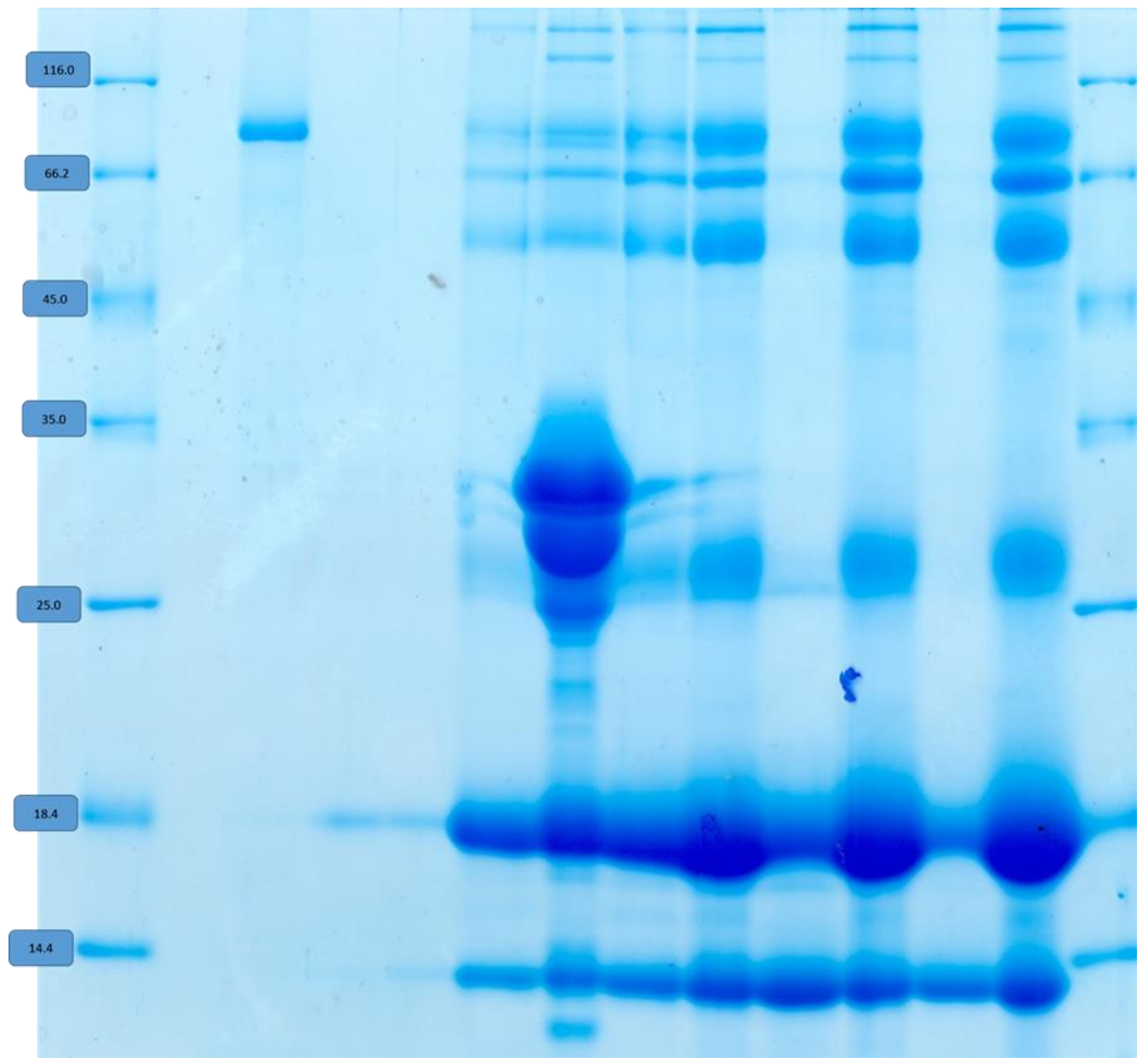

Figure 4. Electropherogram of milk and whey fractions: $(1,13)$ molecular weight markers, (2) lactoferrin standard sample, (3) whey fraction $(5-100 \mathrm{kDa}),(4)$ whey fraction $(\leq 50 \mathrm{kDa}),(5)$ whey, (6) defatted milk, $(7,10,12)$ - whey fraction $(\geq 100 \mathrm{kDa}),(8)$ whey fraction $(\geq 50 \mathrm{kDa}),(9,11)$ whey fraction $(10-50 \mathrm{kDa})$

\section{References}

1. A.A.Gudok, A.V.Deikin, Russian Scientist, 1(1),3 (2017)

2. E.D.Weinberg, Expert OpinInvestig Drugs, 12(5),841 (2003)

3. E. Baker, H.Baker,Biochimie,91(1), 3 (2009)

4. GRAS Notice (GRN) No. 669, FDA COMPLIANCE. URL: https://www.fda.gov/Food/IngredientsPackagingLabeling/GRAS/NoticeInventory/defa ult.htm (reference date: 19.04.2021)

5. Note for guidance on validation of analytical procedures: text and methodology (CPMP/ICH/381/95), European Medicies Agency/ AIP Publishing. URL: https://www.ema.europa.eu/en/documents/scientific-guideline/ich-q-2-r1-validationanalytical-procedures-text-methodology-step-5_en.pdf (reference date: 19.04.2021).

6. L.A.Osterman (Nauka, Moscow, 1981 